\title{
Tacit collusion, firm asymmetries and numbers: evidence from EC merger cases*
}

\author{
Stephen Davies ${ }^{\dagger} \&$ Matthew Olczak ${ }^{\ddagger}$ \\ with Heather Coles $^{\S}$
}

May 2010

\begin{abstract}
This paper estimates the implicit model, especially the roles of size asymmetries and firm numbers, used by the European Commission to identify mergers with coordinated effects. This subset of cases offers an opportunity to shed empirical light on the conditions where a Competition Authority believes tacit collusion is most likely to arise. We find that, for the Commission, tacit collusion is a rare phenomenon, largely confined to markets of two, more or less symmetric, players. This is consistent with recent experimental literature, but contrasts with the facts on 'hard-core' collusion in which firm numbers and asymmetries are often much larger.
\end{abstract}

JEL Classification codes: L13, L41

Keywords: Tacit collusion, collective dominance, coordinated effects, European mergers, asymmetries

*We would like to thank, but not implicate, participants in seminars at Bonn, Budapest, Valencia (EARIE 2007), the OFT, Reading, and UEA (NIE 2007), Malcolm Coate, Morten Hviid and Alessandro Sembenelli, and two anonymous referees and an editor of this Journal for helpful comments on earlier drafts. The support of the Economic and Social Research Council is also gratefully acknowledged.

${ }^{\dagger}$ Corresponding author. Centre for Competition Policy, University of East Anglia, Norwich NR4 7TJ, UK. s.w.davies@uea.ac.uk +441603592715

†Economics and Strategy Group, Aston Business School, Aston University, Birmingham, B4 7ET, UK. m.olczak@aston.ac.uk

${ }^{\S}$ Heather Coles was working with Steve Davies on a much earlier draft of this paper at the time of her tragic death in 2005. The authors would like to dedicate this paper to Heather. 


\section{Introduction}

It is the received wisdom that tacit collusion is more likely the fewer leading players there are in a market, and the more symmetric they are. This was recognised long ago in the traditional Structure-Conduct-Performance paradigm, and was subsequently formalised with the theory of repeated games $^{1}$. However, in spite of theoretical consensus, the empirical literature offers few stylised facts on the most simple of questions - how few is few, and how symmetric is symmetric ${ }^{2}$ ? Given that the concept is somewhat elusive, this is probably unsurprising, but it certainly contrasts with the rich empirical literature on hard-core collusion (see, for example, Harrington, 2006(a) and Levenstein and Suslow, 2006).

The current paper addresses this gap in empirical knowledge, albeit in an indirect way, using a carefully constructed database of case decisions by a Competition Authority (CA), the European Commission, in all of which tacit collusion appears to have been an issue. Unlike for hard-core cartels, there is no existing body of cases where CAs have intervened to combat existing tacit collusion. The reason is, quite simply, that tacit collusion is not illegal. Nevertheless, there is one area of policy where CAs do assess the prospects that tacit collusion may arise - merger control for cases potentially involving coordinated effects/collective dominance. In most major jurisdictions, there is a reasonably large number of such cases, and this provides the scope for constructing a database sufficiently large to support econometric analysis designed to uncover stylised facts about the sorts of markets and market structures that a CA associates with tacit collusion.

The paper uses this database to identify the implicit model of market

\footnotetext{
${ }^{1}$ For examples, see Scherer and Ross (1970) and Ivaldi et al. (2003) respectively.

${ }^{2}$ This is not to deny the large empirical literature which uses structural models, to deduce from observed conduct whether firms are behaving in a tacitly collusive manner in particular markets (see, for example, Bresnahan (1989), Slade (1987), and Slade (2004)). However, by its nature, that literature can not easily provide generalized stylized facts to answer questions such as those in our first paragraph.
} 
structure (as reflected in firm numbers and size asymmetries) used by the European Commission, when deciding whether mergers are likely to have coordinated effects. Although this is straightforward, it is nevertheless novel and of considerable policy relevance. In spite of a large literature which attempts to econometrically explain the decisions of CAs in various areas of policy, there is no such study dedicated specifically to coordinated effects. This is an important omission within the policy literature, given the controversies of recent years, for example, concerning the Commission's decisions in celebrated cases such as Airtours (M.1524, 1999), the academic critique of the Nestle-Perrier case (Compte et al., 2002), and the 2004 revision to the European Merger Regulation. Of course, it does not necessarily follow that this model tells us much about the conditions under which tacit collusion actually occurs. At best, we will only identify the Commission's own conjectures and understanding of tacit collusion. Its model may, or may not, be the 'true' one. We return to this issue at the end of the paper.

As a preliminary, we need to be clear on terminology. Throughout, the terms 'collective dominance' and 'coordinated effects' 3 are used synonymously - both refer to mergers where it is anticipated that the firms remaining in the market post-merger (including the merged firm) would be likely to coordinate their actions. This need not, and generally will not, entail explicitly agreed strategies or information exchange. Rather, what is envisaged is as captured perfectly by Chamberlin's (1929) oft-quoted words of 80 years ago:

"If each (firm) seeks his maximum profit rationally and intelligently, he will realize that when there are only 2 sellers, his own move has a considerable effect upon his competitors, and that it makes it idle to suppose that they will accept without retaliation the losses he forces upon them. Since the result of a cut by any one is inevitably to decrease his own profit, no one will cut, and

\footnotetext{
${ }^{3}$ Hereafter, we employ the European terminology, collective dominance, merely because our data derive from European cases over the period when this was the European Commission's common parlance for coordinated effects. Since the revision to the merger regulation in 2004, 'coordinated effects' has become common terminology, even within Europe.
} 
although the sellers are entirely independent, the equilibrium result is the same as though there were a monopolistic agreement between them." (p.85)

This fits comfortably with the contemporary interpretation of tacit collusion as a potential equilibrium outcome from a dynamic non-cooperative game, which is well summarised, for example, by Ivaldi et al. (2003) writing for the European Commission. They derive the standard results on the market conditions under which tacit collusion is likely, including: transparent prices, frequent interaction, entry barriers and absence of countervailing buyer power and, most important for present purposes, fewness of competitors and symmetry of market shares. As Ivaldi et al. note, market share asymmetry is important, not only in its own right, but also because of the underlying asymmetries it may reflect. In recent years, the theoretical literature has explored various possibilities: Rothschild (1999) on costs, Compte et al. (2002) on capacity, Kühn (2004) on the number of products, and Vasconcelos (2004) on capacity/costs. Although the details of these models vary, the underlying mechanism always works through the asymmetry this causes between firms in the incentives and ability to collude/punish/deviate.

Thus, the purpose of the present paper is to identify how far these theoretical expectations are mirrored, in terms of firm numbers and size asymmetries, in the European Commission's merger decisions on collective dominance.

The paper starts with a simple reading of decision-making by the CA, based on its published merger guidelines. When deciding whether a given merger will require remedies or prohibition, the CA considers all markets in which there are currently overlaps between the merging parties. For each market, it has the choice between non-intervention, or declaring a theory of harm, and, if the latter, whether it is single or collective dominance (unilateral or coordinated effects). The likelihood of competitive harm depends upon: i) market shares and concentration levels including asymmetries, and 
ii) a checklist of other market conditions, including barriers to entry, absence of countervailing buyer power, price transparency and capacity. This checklist must be satisfied, if the CA is to intervene; if it is satisfied, the theory of harm then depends on the configuration of market shares. Our objective is to identify the CA's implicit model of the role of market shares in cases where the checklist is satisfied.

From the population of 2,425 merger reports published by the Commission, 1990-2004, a sample is identified in which the Commission appears to have seriously considered collective dominance as a potential outcome. These mergers are nearly all multi-market, and, in aggregate, they account for 386 different markets - these are the core data of the paper. Post-merger, most of these markets would have had no more than two or (much less frequently) three major players, and with only one exception, the Commission never identified collective dominance with a market of more than two major firms. In the event, the Commission intervened to prevent collective dominance in only $11 \%$ of these markets; in a further $19 \%$ it concluded that single dominance was the appropriate theory of harm, and in the remainder it did not intervene at all, in $40 \%$ because one or more of the checklist conditions was not satisfied.

Building on these descriptive facts, we present a simple econometric methodology designed to predict the nature of the Commission's decision in any market in terms of market shares and concentration, acknowledging the necessary status of the checklist variables. To aid specification of market structure, we introduce a simple geometrical device - the 'oligopoly triangle' - which shows that the key features of market structure can be represented parsimoniously by two key statistics - the sum and ratio of the two leading firms' market shares. Excluding all markets in which the Commission declares that the checklist factors were not satisfied, a multinomial logit estimator on the remaining markets correctly predicts $80 \%$ of the Commission's decisions, including those on collective dominance. 
The remainder of this section briefly surveys the related empirical literature; section 2 presents our reading of the CA's merger decision-making, as captured by its published guidelines; section 3 describes the database; section 4 presents 'the oligopoly triangle'; section 5 describes our econometric methodology, and section 6 reports the results. Section 7 summarises our findings on the Commissions implicit model of merger decisions, and Section 8 draws some contrasts and parallels with the experimental literature on collusion and the empirical literature on cartels.

\section{Previous literature}

There is a sizeable empirical literature which attempts to explain CA decisions in various areas of competition policy, in terms of the structure and other characteristics of the firms and markets concerned. Many are devoted to mergers. Early work by Coate and McChesney (1992), Khemani and Shapiro (1993), and Weir $(1992,1993)$ focused on the US, Canada and the UK, but recently it is the decisions of the European Commission which have attracted increasing attention. The recent studies closest to ours are Bergman et al. (2005) for the EU, Coate (2005) and Coate and Ulrick (2006, 2009) for the US, and Bergman et al. (2009) comparing the EU and the US4.

Although these studies differ in their precise objectives and detail, most can be stylised as follows. The typical database is a large number of different merger decisions; the unit of observation is the individual merger, and the dependent variable is the CA's 'decision', invariably binary: intervention or non-intervention. Explanatory variables invariably fall into two

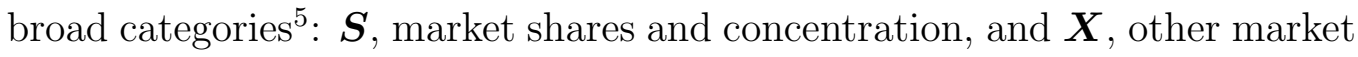
characteristics, such as entry barriers, buyer power, excess capacity.

The current paper attempts to develop this literature in at least three re-

\footnotetext{
${ }^{4}$ Other similar studies include: Davies et al. (1999) for abuse of dominance in the UK; Carree et al. (2008) for European antitrust cases; Grout and Sondregger (2005) for cartels; Lindsay et al. (2003) and Bougette and Turolla (2008) for EC mergers.

${ }^{5}$ Some studies include other sundry, mainly institutional/political, variables, such as the identity of the EC Competition Commissioner in EU cases, and nationality of firms.
} 
spects. First, many previous studies employ the CA's decision at the merger level as the unit of observation. However, this fails to acknowledge that most mergers impact on a number of different markets - particularly in the EU, where the Commission usually makes a judgment for each member state and often intervenes in some, but not all, markets covered by a given merger ${ }^{6}$.

Second, most studies do not distinguish unilateral and coordinated effects, even though merger samples of this sort will inevitably include some potential coordinated effects mergers. The implicit assumption - that the same model applies for both types of merger - is implausible. Coate (2005) and Coate and Ulrick $(2006,2009)$ are an exception, but their criteria for identifying, and their models for explaining, the two types of merger are questionable ${ }^{7}$. Bergman et al. (2005) also acknowledge coordinated effects by including an explanatory dummy variable, reflecting whether or not 'the Commission finds that the firms will be collectively dominant after the merger'(p.726), but this implies just a simple shift effect, as compared to unilateral effects, rather than acknowledging that a quite different model of market structure is required.

In the present paper, we use the individual market within each merger as the unit of observation. By allowing for within-merger heterogeneity, we add a potentially rich source of extra information. We also distinguish between theories of harm, which may well vary - not only between mergers but also between markets within the same merger.

\footnotetext{
${ }^{6}$ In some studies (Bergman et al. (2005), Bergman et al., (2009)), each merger is represented by the market in which the 'most serious' competitive concerns are deemed to occur. Here, while the market is the unit of observation, it is still the case that withinmerger (across markets) heterogeneity is ignored.

${ }^{7}$ They identify potential coordinated effects with those mergers in which the product is homogeneous and there are at least three rivals to the merging firms, or where the product is heterogeneous but the merging parties have a market share no more than $35 \%$. All other mergers are assumed to have potential unilateral effects. They then test a model in which the CA bases its judgement in unilateral cases on the number of rivals, and in coordinated effects markets on the Hirschman-Herfindahl index $(H H I)$ index. We argue below, in section 4, that, while unilateral effects are indeed more likely the higher is $H H I$, the reverse may be true for coordinated effects.
} 
A third difference is our treatment of the $X$ characteristics. In most previous studies, these achieve high statistical significance, but they raise doubts of measurement and interpretation. Typically, these are represented by simple categorical variables (e.g. low/high entry barriers), where the category is decided from the researcher's reading of the published merger reports. As authors admit (e.g. Bergman et al. (2005), p.725), this is necessarily based on their own subjective reading of texts which are published by the $\mathrm{CA}$ itself, and this raises the doubt that the $\mathrm{CA}$ will inevitably be self-justifying in its written explanations of its decisions ${ }^{8}$; for example, it is unlikely that any CA would ever block a merger in spite of admitting that barriers to entry are low. In the current paper, we argue that it is unnecessary to attempt to 'measure' these $\mathrm{X}$ characteristics if the $\mathrm{CA}$ uses them in the form of a checklist of necessary conditions which must be satisfied if it is to intervene. Rather, we argue that these factors are better handled empirically by careful sample selection, excluding markets where the CA reports that the checklist is not satisfied.

\section{A reading of the CA's decision-making}

The European Commission publicly sets out the basis of its decision making in its horizontal merger guidelines $(2004)^{9}$. These explain that there are three parts to its assessment of any merger.

i. market share and concentration levels (para 14-21)

\footnotetext{
${ }^{8}$ This criticism has also been made by Duso et al. (2007), pp.457-8. Their solution is to use an event study methodology in which stock market reaction provides an independent assessment of the competitive effects of a merger.

${ }^{9}$ http://eur-lex.europa.eu/LexUriServ/site/en/oj/2004/c_031/c_ 03120040205en00050018.pdf. See also the US guidelines at http://www.usdoj. gov/atr/public/guidelines/hmg.htm. Although the EC guidelines were only published in 2004 - there were no earlier published guidelines - it is our understanding that they represent prevailing practice in the years before 2004. Possible exceptions to this statement are that neither the efficiency nor the failing firm defences had featured significantly in decisions prior to 2004.
} 
These include the market shares of the merged entity and its main rivals, and the level of market concentration $(H H I)$; they refer to both the likely post-merger levels and changes implied compared to premerger $^{10}$;

ii. possible anti-competitive effects (paras 22-63)

The Commission enumerates two main theories of harm - non-coordinated and coordinated effects (single and collective dominance). The likelihood of harm depends on a number of factors, including market shares, closeness of substitutes, switching possibilities etc. The discussion of collective dominance stresses the need for coordination and three necessary conditions - monitoring, discipline and outsider response. Three key factors are emphasised - symmetry of firms, price transparency and the extent of spare capacity. Price transparency is cited as crucial for effective monitoring. The role of spare capacity is more equivocal, mirroring the ambiguities of economic theory - while spare capacity is necessary for credible punishment, it also raises the incentive to deviate (Compte et al., 2002.) Capacity also plays an important potential role in unilateral effects, since insufficient spare capacity makes it less likely that rivals can soften any price-raising effects of the merger by their own post-merger expansion.

iii. extenuating conditions (paras 64-91)

The guidelines also point to four additional factors which may extenuate the potential harm caused by the merger. Two ('efficiencies' and 'failing firm') do not feature tellingly in any of our sample mergers,

\footnotetext{
${ }^{10}$ The EC follows the general convention, as do we below, by calculating the post-merger market share of the parties by simply adding their pre-merger shares. This is not the same as the actual post-merger share, of course, since the report is ex-ante - produced at the time of the proposed merger. Also, it does not acknowledge a general result from the theoretical equilibrium merger literature - typically, a merging firm will choose to produce less post-merger than did the sum of the constituent firms pre-merger (Farrell and Shapiro, 1990, Salant et al., 1983.)
} 
but the other two, 'countervailing buyer power' and 'entry' are both prominent. The Commission clearly places great store by these factors, giving the strong implication that it will not declare any theory of harm in any market in which new entry is easy, or in which buyers possess significant buyer power ${ }^{11}$.

This reading suggests that the following is an accurate stylisation of the Commission's assessment of any horizontal merger: for each market covered by the merger in which the parties have overlapping market shares, it makes a choice between three alternative decisions ${ }^{12}$ :

- NI: Non intervention

- SD: Intervention for single dominance

- CD: Intervention for collective dominance

This choice is based on an assessment of the likelihood of competitive harm, taking into account various merger and market characteristics which can be characterised using the above $S$ and $X$ notation:

- $\boldsymbol{S}$ : a vector of market share and concentration variables, including size asymmetries. These include prospective post-merger levels and the magnitude of changes, pre- to post-merger.

- $\boldsymbol{X}$ : a checklist vector of market characteristics, including: entry conditions, buyer power, price transparency and capacity constraints.

The strong implication running through the guidelines is that these $X$ characteristics amount to a series of necessary conditions. Thus, the Commission will not find a theory of harm, regardless of market structure, unless the following checklist is satisfied:

\footnotetext{
${ }^{11}$ This emphasis contrasts with its discussion of some other variables, which it explains, when 'taken separately are not necessarily decisive' (para. 26.)

${ }^{12}$ It is assumed that, conceptually, the Commission adopts the same approach in both phases 1 and 2, although the depth of analysis and data collection is typically more extensive in the longer phase 2. This assumption appears to be confirmed by results reported later in section 6 .
} 
- barriers to entry into the market

- no significant countervailing buyer power

- price is transparent (for collective dominance)

- capacity of rivals is constrained, such that they are unable to expand sufficiently rapidly post-merger (in single dominance cases), or that capacity constraints do not render punishment non-credible (in collective dominance cases.)

This reading is consistent with Coate and McChesney's (1992) study of decisions made under the US 1982/1984 merger guidelines, in which they conclude that 'the evidence suggests that entry barriers are virtually a necessary condition for a merger challenge.'(p.283)

There may also be sundry other factors which play a cumulative role in framing the Commission's decision in any particular case (for example, rapidly changing or volatile market shares), but these do not have the status of necessary conditions - to anticipate, they do not appear to be routinely discussed or factored into the decisions process. They are also difficult to measure and are excluded from the econometric analysis below.

\section{EC mergers involving the potential for col- lective dominance}

Since the European Merger Regulation (ECMR) came into effect in 1990, the Commission has published decisions on approximately 3000 mergers. The Regulation was revised in 2004, and to avoid any danger of a structural break, we focus here on 1990-2004 (2425 mergers). Merger appraisal may involve one or two phases. Phase 1 is an initial investigation, and in $90 \%$ of cases this is sufficient to confirm that no competition concerns are raised and mergers are cleared. In about half of the remainder, commitments (remedies) are agreed in Phase 1 and the merger is then allowed to proceed. However, in remaining 
cases, appraisal goes to a more extensive Phase 2 investigation. Here, remedies are much more likely and in the extreme, the merger has been blocked entirely. Although outright prohibition is relatively uncommon, in about 200 other cases, the Commission required commitments from the merging parties to remove specific competition concerns (usually, but not always by divesting some assets). Hereafter, the term 'intervention' is used to encompass not only full prohibition but also cases of commitments/undertakings/remedies agreed or imposed in either Phase ${ }^{13}$.

From this population, we have assembled a targeted sample of cases to include only those mergers in which the Commission appears to have seriously contemplated collective dominance as a potential theory of harm. All merger reports in the population ${ }^{14}$ were word-searched for the use of one or more of the following phrases: collective dominance, (tacit) collusion, joint dominance, oligopolistic dominance or coordinated effects. This isolated 94 candidate mergers, but closer textual examination revealed that in 32 the above phrases were only used in a cursory manner - typically in a throwaway single sentence or short paragraph, revealing that the Commission had easily dismissed the possibility.

This leaves 62 mergers, for each of which the text of the Commission's report includes a non-trivial discussion of the possibility that the merger might lead to collective dominance in at least one market. These mergers form the database for the current paper. It should be stressed that this search process has merely identified all mergers in which collective dominance was seriously considered as a potential problem in at least one market.

\section{Characteristics of the sample mergers}

Clearly, collective dominance arises only very infrequently as a potential issue: in only $2.5 \%$ of all cases. Because we confine our attention to only cases

\footnotetext{
${ }^{13}$ See Davies and Lyons (2007) for more discussion of the ECMR and remedies.

${ }^{14}$ Reports available at http://ec.europa.eu/competition/mergers/cases/, consulted December 2005.
} 
where there are market overlaps between merging firms, all mergers were purely horizontal . Most mergers are multimarket, involving more than one product market, and certainly for the EU, more than one geographical market. Here, the 62 mergers covered 386 different markets in which there were overlaps, and for which there are useable data. Thus, the average merger covers about six different markets. However, in nearly all cases, the different markets are very closely related in product space - either because the merger impacts on the same product market in different Member States, and/or because, even when there is more than one product market, they are closely related $^{15}$.

\section{Concentration}

Markets would typically involve only one, two or sometimes three major players post-merger ${ }^{16}$. Therefore, not unexpectedly, nearly all would be highly concentrated post-merger. As an illustration, suppose a 'significant' market share is defined to be more than $15 \%$. If so, post-merger there was just 1 sample market in which there would be five significant players; 9 quadropolies; 70 triopolies; 199 duopolies; and 95 monopolies. While $15 \%$ is an arbitrary yardstick, any plausible alternative would yield a qualitatively similar conclusion: markets in this sample are typically very small-number oligopolies. Post-merger, the large majority (more than $75 \%$ on our criterion) would be either monopoly or duopoly; the other $25 \%$ would be triopolies or, in a very few cases, quadropolies.

\footnotetext{
${ }^{15}$ In terms of the Commission's NACE classification, all markets covered by each merger belonged to the same 4-digit industry for 54 mergers, and seven involved only two 4-digit industries.

${ }^{16}$ Market share data are taken from the Commission's decision reports. Most include sufficient information to estimate the market shares of the leading players in each market, before and after the proposed merger. However for reasons of business confidentiality, these are often only reported within size bands, e.g. 30-40\%, and in those cases, we take the midpoint of the range. Similarly, in some cases it has been necessary for us to approximate the magnitudes of $S 3, S 4$ and $S 5$. This is unavoidable, but inevitably adds a degree of imprecision to all results reported in this paper.
} 


\section{The Commission's decisions}

In its decision reports, the Commission spells out the theory of harm for each market in which it intervenes - either single or collective dominance. Figure 1 summarises. As can be seen, although the defining feature of this sample is that it includes all mergers in which the Commission seriously considered the possibility of collective dominance, in the event, it actually intervened on the grounds of collective dominance in only 44 markets. In another 74 it intervened on the grounds of single dominance. In the other 268 markets it judged there to be no competitive harm.

[Figure 1 here]

Most commonly, collective dominance is identified when the post-merger market would include just two remaining 'large' firms: CD-DUO. There is only one case, the infamous Airtours merger in the UK, in which there would be a 3 firm post-merger structure: CD-TRI. Evidently, in the eyes of the Commission, collective dominance (tacit collusion) is effectively a problem associated only with duopoly.

There is also a third class of case (CD-LINKS): where the merger would lead to a market structure with only a few significant players, where two or more are 'structurally linked' in some way. Usually, the links refer to common shareholders/shareholdings amongst a pair of firms, but occasionally, to nonownership arrangements, such as petrol swaps amongst the major retailers. In all such cases, the Commission essentially views the linked firms as a single entity for this purpose ${ }^{17}$. In the econometrics below, we treat this as equivalent to single dominance decisions, in which the shares of linked firms have been combined.

\footnotetext{
${ }^{17}$ For instance, in Rhodia/Donau Chemie/Albright \& Wilson (M.1517, 1999), para.54, 'Rhodia has structural links with Prayon... (and it) has been suggested that Rhodia and Prayon are commercially regarded as one block in the market. If this is true one might add Prayon's ... market share to the parties'.
} 
In its decision reports, the Commission also sometimes spells out the nature of the tacit collusion that it anticipates would occur post-merger. In some cases this relates to price, in others to capacity and in others to market sharing. The markets involved are most frequently in the manufacturing sector, and within this, the production of industrial gases. In one case where the Commission intervened on CD grounds, reference is made to previous cartel behaviour in a related market ${ }^{18}$.

\section{Incidence of $X$ factors}

The decision reports also invariably explain the reasons for the Commission's decision in each market. Table 1 shows the frequencies with which it cites the non-fulfillment of the checklist $X$ factors as the reason for non-intervention. As can be seen, the most frequent explanations are that there is easy entry into the market or that buyers have significant buyer power; non-transparent price is also a frequent explanation - in this case, exclusively in markets in which there might otherwise have been coordinated effects. Non-fulfillment of one or more factor is cited in more than half (154) of all non-intervention markets, and while more than one factor is sometimes cited, in the majority of markets (51\%), it is justified on the basis that just one checklist condition is not satisfied. This supports our reading of the guidelines - each of these factors represents a necessary condition in the eyes of the European Commission.

[Table 1 here]

\footnotetext{
${ }^{18}$ Air Liquide/Messer Targets (M.3314, 2004) in the industrial gas market. However, in Pilkington-Techhint/SIV (M.358, 1993) in flat glass manufacturing, the Commission did not intervene despite evidence of previous cartel behaviour in a related market.
} 


\section{Depicting market structures: the oligopoly triangle}

This section explores how best to specify market shares and concentration in order to identify the nature of the Commission's modelling.

Given that nearly all markets in this particular sample would be monopolistic, duopolistic or triopolistic post-merger, and that generally the Commission associates collective dominance with markets of only two significantly sized firms, there is a simple way of depicting the prospective market structures in the present context. This entails plotting the post-merger market share of the \#1 ranked firm against that of the \#2 ranked firm, post-merger, as in figure 2 .

\section{Literal triopoly}

In a market with $N=3$, with firms ranked by their market shares, $S 1$, $S 2$ and $S 3$, the point $(S 1, S 2)$ must provide a complete characterisation of structure in that market.

[Figure 2 here]

Note first, that $(S 1, S 2)$ must lie in the small triangle $A B C$, bounded by the three lines shown in Figure 2.

\section{Proof}

Since $S 1 \geq S 2$, the point must lie on or above the symmetry diagonal, $S 1=S 2$; since $S 1+S 2 \leq 100$, it can not lie outside the downward sloping diagonal $S 1=100-S 2$; and since $S 2 \geq S 3$, by trivial manipulation, $S 2 \geq$ $100-S 1-S 2$, i.e. $S 1 \geq 100-2 S 2$, so the point must lie no lower than the line $S 1=100-2 S 2$.

The corners of $A B C$ (hereafter, the 'triopoly triangle') identify the three limiting structures: monopoly (MON), symmetric duopoly (DUO) and symmetric triopoly (TRI). More generally, the location of $(S 1, S 2)$ reveals: (i) 
the level of concentration (if measured by $S 1+S 2$ ), which is greater the closer is the point to $A B$ (ii) the extent of asymmetry between $S 1$ and $S 2$, which is higher further away from $B C$ and (iii) the extent of asymmetry between $S 2$ and $S 3$ which is higher moving from $C$ to $B$.

This diagram can also be used to reveal an important property of the $H H I$ index. The quadratic locus of $(S 1, S 2)$ pairs for a given value of the index, $H H I_{O}$, is easily derived as ${ }^{19}$ :

$$
S 1^{2}+S 2^{2}-100 S 1-100 S 2+S 1 S 2+\left(10000-H H I_{O}\right) / 2=0
$$

The family of such curves is shown in figure 3, with higher curves denoting higher values of $H H I$. Since each curve is downward sloping (at its maximum at intersection with $A C$, then declining monotonically until its intersection with $A B$, movements in a north-easterly direction towards $A B$ will increase $H H I$, confirming its traditional role as an increasing measure of concentration. On the other hand, it is clear that the index is a poor indicator of symmetry: as structures become more symmetric, such as at $B$ or $C$, the $H H I$ index actually falls ${ }^{20}$. HHI does not discriminate between structures with very different degrees of symmetry; for example, the curve for $H H I=5000$, shown in the figure, is consistent with both asymmetric triopoly $(66.7,16.7,16.7)$ and perfectly symmetric duopoly $(50,50)$.

[Figure 3 here]

\section{$N>3$}

Interpretation of the triangle becomes less clear-cut when there are other smaller firms in the market (with aggregate share F). So long as $F+S 3 \leq S 2$,

\footnotetext{
${ }^{19}$ This is derived from $H H I_{O} \equiv S 1^{2}+S 2^{2}+S 3^{2}$, substituting $S 3 \equiv 100-S 1-S 2$ and re-arranging.

${ }^{20}$ It is easily shown that $H H I=\left(C^{2}+1\right) / N$, where $C$ is the coefficient of variation of market share, an obvious measure of size inequalities, so, for given $N, H H I$ is positively related to inequality.
} 
then $(S 1, S 2)$ remains within the triopoly triangle, but there is now an indeterminacy on the relative sizes of $S 3$ and $F$ : for example, point $C$ can not discriminate between literal triopoly and symmetric duopoly coupled with a large fringe. More generally, with a more sizeable fringe, markets will be located below $A C^{21}$, and the diagram alone is insufficient to tell us anything beyond the combined share and relative sizes of $S 1$ and $S 2$. However, since most markets in this sample would have only one or two significant players post-merger, and the Commission has only in one instance judged a market to be collectively dominant by virtue of three large players, it remains true that the location of $(S 1, S 2)$ provides an indication of concentration $(S 1+S 2)$ and the key asymmetry between $S 1$ and $S 2$.

\section{Fitting Commission decisions to the triangle}

Figure 4 uses the triangle to depict the market structures and decisions for the present sample. Note that $S 1$ and $S 2$ denote the prospective post-merger market shares of the number 1 and 2 ranked firms - in some cases the merged firm will be \#1, in others \#2. First, Figure 4(a) shows all 386 markets, distinguishing markets with and without interventions. Interventions appear to be more common within the literal triopoly segment of the diagram, but it is apparent that neither high concentration nor size symmetries are sufficient conditions for intervention, and this is unsurprising given that the $X$ factor checklist should also be satisfied before the CA intervenes. The impact of the $X$ factors is revealed in Figure 4(b), which excludes all 154 markets (Table 1) in which the EC explicitly justified a decision not to intervene on the grounds that the checklist was not satisfied. With these markets excluded, the role of concentration (closeness to the upper limit of the triangle) and symmetry between $S 1$ and $S 2$ (closeness to the upper sloping diagonal) become more sharply into focus. Figure 4(c) then shows only the intervention markets, but now distinguishing single from collective dominance. There is now a clear

\footnotetext{
${ }^{21}$ Davies and Olczak (2008) show how the area below AC can be segmented to reveal the likely size of the fringe, relative to $S 1$ and $S 2$.
} 
pattern, with very few interventions against collective dominance occurring very far from the main diagonal.

[Figure 4 here]

\section{Empirical methodology}

Based on the above readings of the guidelines and decisions, and the results of the triangle plots,the CA's decision-making is now formalised simply as follows. The decision for market $i$ in merger $j$, (subscripts suppressed) is denoted by $y=k$, where $k=N I, S D$ or $C D$. The probabilities of the three outcomes may be written as:

$$
\begin{gathered}
\operatorname{Pr}(k \mid X=0)= \begin{cases}1 & \text { for } k=N I \\
0 & \text { for } k=S D, C D\end{cases} \\
\operatorname{Pr}(k \mid X=1)=\operatorname{Pr}\left(U^{k}>U^{l}\right) \text { for all other } l \neq k
\end{gathered}
$$

where $X$ denotes the outcome of applying the checklist: $X=0$ if the checklist is not satisfied, $X=1$ if the checklist is satisfied. $U^{k}$ denotes the CA's assessment of the probability that the post-merger structure will potentially

lead to single dominance, collective dominance or neither. $U^{k}=f(S)$ where $S$ is a vector of market structure/concentration characteristics.

In other words, if the checklist of necessary $X$ conditions is not satisfied (for example, because new entry is easy), the Commission will conclude that the merger will lead to no competitive harm and not intervene. If all checklist conditions are satisfied, there exists a potential for competitive harm, and it then draws on the potential post-merger configuration of market shares to decide which of SD, CD or NI is most probable.

Since we assume that the Commission makes a simultaneous choice between three alternative options, and the sample includes a relatively large incidence of all three alternatives, the multinomial logit is an appropriate es- 
timator (Greene, 2008, ch. 23). This requires the assumption of the independence from irrelevant alternatives (IIA), and this will need to be confirmed empirically. Below, we also experiment by replacing simultaneous choice with an alternative two-stage decision process.

In order to estimate this model, we need to specify: (i) the arguments in $f(S)$ and (ii) a treatment of the checklist which recognises the assumption that that $X$ variables are necessary conditions.

\section{Market shares and concentration}

The triangle scatters in figure 4 suggest an obvious specification of the $\mathrm{S}$ vector, which is to include two simple measures, each based on data on the prospective post-merger shares of the largest two firms ${ }^{22}$ :

- $S U M=S 1+S 2$, the sum of the shares of the two largest players post-merger, as a measure of concentration, and

- $\operatorname{RATIO}=S 2 / S 1$, the ratio of their shares.

$S U M$ is a measure of concentration (the two firm concentration ratio) and RATIO is a measure of their symmetry ${ }^{23}$.

Although this is our preferred specification, we will also experiment with two alternatives. The first is to employ just the conventional $H H I$ index. As explained in the previous section, the HHI index is not a measure of size symmetries, and we would not expect it to be a good discriminator between single and collective dominance if the CA does indeed take into account symmetry in its decisions. Therefore, a second alternative is to employ a hybrid specification, with $R A T I O$ also included alongside $H H I$. This

\footnotetext{
${ }^{22}$ In general, one might expect that the shares of the 3rd largest and other smaller firms might also play a role, but, unreported experiments distinguishing $S 3$ from the fringe of smaller firms add no explanatory power to the estimated model.

${ }^{23}$ While $S 2 / S 1$ is an admittedly ad hoc measure of symmetry, it is a natural candidate. For example, in a repeated duopoly game with grim punishment strategies, Ivaldi et al. (2003) show that collusion requires that the discount factor should be no less than $S 1$, and is therefore most likely where $S 1=S 2$, and $R A T I O=1$.
} 
should achieve a similar explanatory power to that achieved with $S U M$ and RATIO, since HHI and SUM are merely alternative indexes of concentration. However, there are grounds for expecting $S U M$ and RATIO to achieve a marginally closer fit than HHI and RATIO for collective dominance decisions, since the CA typically associates tacit collusion with just the two leading two firms, and $S U M$ (the two firm concentration ratio) captures their importance more precisely than $H H I$ (which is a better summary index of the entire size distribution.)

\section{The checklist of $X$ factors}

Given our assumption that the Commission treats these as necessary conditions for intervention, our treatment of the checklist $X$ factors is straightforward: we exclude from the estimation the 154 markets in which the CA explains non-intervention in terms of the checklist not being satisfied (Table 1). Potentially, this treatment might run the risk of sample selection bias if, instead of being strictly necessary, the $X$ variables have a contributory, but not necessarily binding, effect on decisions. In that case, exclusion of these observations and omission of the $X$ variables from the estimated equation, would lead to biased coefficient estimates. That would imply that the Commission was willing to 'trade-off' the $X$ factors against, say, concentration for example, it might intervene in a market, in spite of acknowledging that there are some barriers to entry, because concentration is particularly high.

We can check for this possibility by returning to the Commission's decision reports, but now for the 118 intervened markets, for evidence that the Commission sometimes intervenes even where there is easy entry, significant countervailing buyer power, non-transparent prices (in collective dominance cases) or insufficient rival capacity. A close reading of these reports reveals no instances of such trade-offs. Indeed, we can only identify three markets where the report includes a potential ambiguity on whether a particular checklist factor has been satisfied, but even in these cases the Commission's conclu- 
sion is that, on balance it is. Thus, in Candover/Cinven/BertelsmannSpringer (M.3197, 2003 para 62) there was the possibility that the large (pharmaceutical) buyers might enjoy countervailing power, but the Commission rejected this because buyers had no outside option since they "can only shift their marketing budget away from advertising in publication to a small extent as advertising in specialised medical magazines is a very economical way to get in contact with doctors and other media will not offer an equivalent access to them." In New Holland/Case (M.1571, 1999, para 72 ) it considered the claims of the parties that price is not transparent because "distribution is in the hands of dealers, and sales of new products often involve trade ins of used equipment and price negotiations" but these were rejected on the grounds that "manufacturers can strongly influence retail prices through the setting of wholesale prices and recommended retail prices. Consequently, after the transaction, JCB and the merged entity could both have the incentives and the market power to carry out parallel anti-competitive behaviour." In Allianz/AGF (M.1082, 1998, para 44-45), the Commission conceded that there has been recent entry into the market, but concludes that post-merger the remaining "big players are in a position to use their competitive advantages ... in order to keep out potential new competitors and divide up markets."

In each of these cases, there was clearly discussion and disagreement with the parties on whether or not a particular checklist factor should be 'ticked' - and in each case the Commission concluded that it should be. Even in these three, most marginal of cases, there was no implication that the factor concerned should be considered alongside other factors, and that the Commission might overlook some degree of countervailing buyer power, nontransparency, or entry (respectively) because other factors outweighed their effect. We interpret this as further confirmation of a key assumption in our modelling - that the CA operates a checklist of necessary conditions. Nevertheless, careful interpretation of this assumption is required. Given that the 
purpose of this paper is to identify the reasoning underlying the Commission's decisions, this finding is sufficient for our purpose here. However, we do not need to form any judgement on whether the Commission's assessment (of say the height of entry barriers) was in any sense 'correct', or, indeed, whether it was inappropriate for the Commission to treat each $X$ factor as a separate necessary condition.

\section{Results}

Table 2 reports the multinomial logit estimates of the model, with the three alternative outcomes as SD, CD and NI (as default). The sample comprises 232 observations, i.e. the full sample minus the 154 markets in which the checklist was not satisfied (see Table 1.) 'Goodness of fit' is measured conventionally by pseudo $R^{2}$, the Log pseudo-likelihood, Wald statistics and the percentage of correct predictions. For this purpose, the predicted outcome is defined as the outcome with the highest predicted probability, and the Table records the percentages of the Commission's decisions that the model correctly predicts. Alternatively, the success rate could be measured, for each outcome, by the percentage of the model's predictions of that outcome that are correct. In aggregate the two measures are identical, but they can differ for individual outcomes. However, as will be seen, the model performs virtually identically whichever alternative is used.

Equations I-III include SUM, RATIO and HHI combined variously as explanatory variables; Equation IV also include the prospective post-merger change in concentration and Equation $\mathrm{V}$ adds sundry other explanatory variables for comparability with the previous literature.

[Table 2 here]

\section{Core market share variables}


Equation I reports the result of fitting the model, initially with $S U M$ and RATIO. The signs and significance of the estimated coefficients are as expected: single (SD) and collective (CD) dominance are both significantly more likely the larger is $S U M$; while SD is significantly less likely, and CD significantly more likely, the larger is RATIO. In other words, both forms of dominance are more likely in concentrated markets, while collective dominance is more likely (but single dominance less likely) the more symmetrically sized are the top two firms. The equation achieves a high success rate in terms of correct predictions: $81 \%$ of the Commission's decisions are correctly predicted, including $80 \%$ of the markets in which the Commission finds CD, $77 \%$ for $\mathrm{SD}$ and $84 \%$ for $\mathrm{NI}^{24}$. Inspection of those markets for which the predictions are incorrect reveals no obvious systematic features. An $80 \%$ success rate is satisfactory, bearing in mind the unavoidable approximations in measuring the market share variables (see footnote 20), and the possibility of some time inconsistency in the Commission's decision making over a 15 year period. A Hausman-McFadden chi-squared test on this equation confirms that we can accept the Independence from Irrelevant Alternatives.

The model is then re-estimated in Equation II, with the HHI index now replacing $S U M$ and RATIO. While both types of intervention are significantly more likely the higher is the HHI index, the fit is quite low and this equation fails to correctly predict any CD decisions (except CDLINKS) and only $65 \%$ of SD interventions. This is as expected, given our earlier argument that the $H H I$ index alone is a blunt tool for discriminating between single and collective dominance, and it suggests that the Commission also takes into account the degree of symmetry when making its decisions. This is duly confirmed by Equation III, in which RATIO is added to HHI as explanatory variables - this significantly improves on Equation II (the

\footnotetext{
${ }^{24}$ Measuring the success rate alternatively by the percentages of the model's predictions which are correct, results are very similar - rising slightly to $83 \%$ for CD and $82 \%$ for SD, but falling slightly to $80 \%$ for NI. Similarly, there is very little difference between the two measures of successful predictions in all following equations.
} 
$L L R=85$, which is significant at the $1 \%$ level). In fact, III achieves a fit (in terms of the log-likelihood and pseudo $R^{2}$ ) which is now only marginally lower than in Equation I - again, as might be expected, since I and III differ only in how concentration is measured (the sample correlation coefficient between $S U M$ and $H H I$ is 0.90$)$. Nevertheless, Equation III correctly predicts only $57 \%$ of the Commission's CD decisions (as opposed to $80 \%$ in equation I), suggesting that $S U M$ is the more appropriate measure of concentration in this particular context, where as we have already seen, the CA implicitly associates tacit collusion with just the two largest players ${ }^{25}$.

\section{Changes to concentration}

Since the Commission's guidelines explain that it also takes into account the extent of the change in concentration implied by the merger, as well as the level of post-merger market shares, Equation IV re-estimates our preferred equation I, but now also including the change in concentration, denoted by CHASUM. Unfortunately this rules out a quarter of the sample markets, because the Commission's reports provide insufficient information on the parties' pre-merger market shares ${ }^{26}$. The signs, magnitudes and significance of coefficient estimates on $S U M, R A T I O$ remain substantively unchanged from Equation I, and, in line with expectations, the estimated coefficient on CHASUM is positively significant for both single and collective dominance. Ceteris paribus, the probability of intervention is higher, the larger the change in concentration the merger implies ${ }^{27}$.

\section{Other explanatory variables}

Largely for comparability with the previous related literature, the final equa-

\footnotetext{
${ }^{25}$ Moreover, when both $S U M$ and $H H I$ are included alongside RATIO (not shown in the Table), $H H I$ is insignificant in explaining CD.

${ }^{26}$ In these cases, the Commission only reports the post-merger share of the merged firm (i.e. the sum of the merged parties' pre-merger shares), and not their individual pre-merger shares.

${ }^{27} \mathrm{~A}$ similar result is achieved if the change in the $H H I$ is substituted for $C H A S U M$.
} 
tions (V) adds the following, more institutional, merger-level explanatory control variables to our core equation I:

- MONTI: a dummy variable taking the value of 1 for decisions taken after September 151999 (i.e. for decisions taken under Commissioner Monti)

- $\boldsymbol{N} \boldsymbol{A T I O N} \boldsymbol{A L}$ : a dummy variable taking the value of 1 if the relevant geographical market is national or smaller (as opposed to a World or EEA market)

- $\boldsymbol{B I G 5 E U}$ : a dummy variable taking the value of 1 if at least one of the merging parties is based in one of the five largest member states

- $\boldsymbol{U} \boldsymbol{S}$ : a dummy variable taking the value of 1 if at least one of the merging parties is based in the US

These variables are as discussed and previously employed by Bergman et al. (2005) and Bergman et al. (2009).

Inspection of the estimated coefficients reveals that those on $S U M$ and $R A T I O$ are robust to the inclusion of these variables. An $L L R$ test confirms that this set of variables adds significantly to the explanatory power of the core equation (the $L L$ falls from -123.6 to -111.3 , and the $L L R=24.6$ is significant at the $1 \%$ level. However, the only significant result is a greater tendency for the Commission to intervene on the grounds of single dominance if the market concerned was defined at an aggregate EEA or world level ${ }^{28}$.

In other unreported results, we have experimented with alternative functional forms for the explanatory variables, but they add nothing to predictive power. We have also tested to see whether the model is robust across Phases

\footnotetext{
${ }^{28}$ This is a variable on which we have no strong priors. Perhaps the Commission interprets high concentration at the supranational level as indicative of even higher concentration at the disaggregated level of individual member states, but this would imply at least an element of doubt that the suprational level was the appropriate geographical definition of the market. Both Bergman et al. (2005, Table 4), and Bergman et al. (2009, Table 3 ) find that a similarly defined variable has the opposite, but insignificant, effect on the probability of intervention.
} 
1 and 2. Allowing the coefficients in equation I to differ between the two phases lowers the log-likelihood to -118 , but a likelihood ratio test reveals that this is not a significant improvement at the $5 \%$ level and indeed none of the six estimated coefficients differs significantly between the two phases. Thus there is no evidence to suggest that the Commission applies different models in the two phases. Finally, we also experimented with a two stage probit model, with the first stage explaining whether or not the Commission intervenes, and the second stage explaining the type of intervention (whether $\mathrm{SD}$ or $\mathrm{CD}$ ) in those markets where intervention occurs. When judged by predictive power, this model performs virtually identically to the Multinomial Logit.

\section{Conclusions on the Commission's model of collective dominance}

The European Commission clearly only views collective dominance as a rare occurrence. Over a 15 year period, 1990-2004, covering 2,425 mergers, we have only identified $62(2.5 \%)$ in which the merger report includes a nontrivial discussion of the possibility of collective dominance. Even amongst these cases, the Commission required a remedy to avoid collective dominance in only 44 of the 386 markets (11\%) concerned. Thus, the aggregate probability that a merger might lead to collective dominance in a particular market is only $0.29 \%$.

In assessing the likelihood of collective dominance, the Commission is guided by both market structural variables and a set of other market characteristics: price transparency, buyer power, capacity and entry barriers. It appears that both sets have the status of necessary conditions - the Commission requires not only that the structural indicators are consistent with tacit collusion, but also that the price is transparent, entry is difficult, etc.

\section{Market structure}


On the structural side, both high concentration and reasonably symmetric market shares of the leading players are required. Strikingly, with only one exception, collective dominance has never been associated with more than just two firms. Our results also help quantify what is meant in practice by symmetry. Figure 5 depicts the results from equation I in Table 2 graphically in terms of the oligopoly triangle. The three areas are computed using the estimated parameters, and show for the $(S 1, S 2)$ pairs the decision which the equation predicts as most probable. Collective dominance is most likely only for a relatively small area located near to the point of symmetric duopoly.

[Figure 5 here]

This can be summarised equivalently in numerical terms. First, if the largest firm, post-merger, has no more than a quarter of the market $(S 1<$ $23 \%$ ) the Commission is predicted to not intervene. On the other hand, if it has more than $60 \%$, the predicted decision will always be single dominance. Between these bounds, the share of the second firm comes into play. So long as $S 1<53 \%$, anything is possible, the prediction is: single dominance if $S 2$ is very small, no intervention if $S 2$ is sufficiently large to counteract the potential dominance of the larger firm, or collective dominance as the two firms become more equally sized. For example, at $S 1=40$, the predicted decision will be single dominance for $S 2 \leq 12$, non-intervention for $12<$ $S 2<35$, and collective dominance for $S 2 \geq 35$. Once $S 1$ exceeds $52 \%$, nonintervention is never the predicted choice, and the choice is simply between single and collective dominance. For example, if $S 1=53 \%$, single dominance is predicted unless $S 2>35 \%$.

\section{The checklist $X$ factors}

The market share conclusions are all conditional on the checklist of other necessary conditions being satisfied in the eyes of the Commission: entry barriers, absence of countervailing buyer power, transparent prices and sufficient rival capacity. An important thesis of this paper is that because these 
market characteristics are not only necessary conditions, but also inherently unmeasurable, it is difficult to quantify their importance, or to isolate the CA's underlying market structure model. Our solution has been to exclude all markets from estimation where the CA has implied that the checklist is not satisfied. However, it is possible to assess the relative importance of these $X$ factors in the following way. Applying the estimated equation I from Table 2 to the actual market shares in the 154 excluded markets, we can predict what would have been the Commission's decisions had the checklist been satisfied: in 25 the decision would have been SD and in $32 \mathrm{CD}$. Recalling that there were 44 markets in which the Commission actually judged that the merger would lead to CD, this suggests than in $42 \%(=32 / 76)$ of all cases where the market structure was conducive to tacit collusion, the checklist was not.

\section{Post 2004}

In mid 2004 the European Commission revised the Merger Regulation, establishing a 'significant impediment to effective competition' test for merger regulation. Under this test, interventions still remain possible on SD grounds, but now the Commission has an extra tool - to intervene against unilateral effects even when the merged firm is not singly dominant and coordinated behaviour is unlikely. As explained earlier, to avoid the possibility of a late structural break in our data, we have therefore confined the current study to the period up to mid 2004, with future work planned as data accumulates under the new regulation.

The early signs suggest important changes in the Commission's stance towards collective dominance (now referred to as coordinated effects.) In the period mid 2004 to end 2007, we have identified 19 mergers (covering 334 markets) in which there were interventions and the decision documents reveal that coordinated effects $(\mathrm{CE})$ was seriously considered. In fact, interventions for $\mathrm{CE}$ in these mergers have been extremely rare, occurring in only four 
markets $^{29}$. Applying the model, as estimated in equation I in Table 2, to the market shares in these 334 markets, CE is predicted in 21 markets. However, the Commission did not intervene in 15 of these cases (including 5 on the grounds that the checklist factors were not satisfied), and in 5 others it did intervene, but on the grounds of UE/SD. It is unclear whether this reluctance to find CE should be directly attributed to the revision itself, or caution in the wake of the successful Airtours appeal. Either way, it is consistent with the argument by others (Kühn (2001), Baxter and Dethmers (2006)) that the burden of proof is higher for CE than UE.

\section{Wider implications}

Although our results suggest then that the Commission's decisions are qualitatively consistent with the predictions of repeated game theory - tacit collusion occurs only when firms are few and symmetrically sized - it clearly interprets both 'few' and 'symmetric' very tightly: tacit collusion can only occur in near symmetric duopolies.

Whether or not its interpretation is over-cautious remains unclear, given the absence of any strong stylised facts from the existing empirical literature on tacit collusion, and further work is required. One potentially fruitful approach would be turn to an ex-post evaluation (see for example Ashenfelter et al. (2009) and Carlton (2009)) of subsequent developments, especially prices, in those marginal non-intervened mergers lying just outside the CD area in figure 5 (for example, where post-merger structures involved three main players and/or slightly less symmetric duopolies.) Is there any evidence that post-merger prices rose more rapidly in these markets 'on the cusp' compared to a control group?

In the meantime, however, we note some intriguing perspectives by refer-

\footnotetext{
${ }^{29}$ This excludes cases with structural links between firms and mergers between shipping lines, due to unavailable reliable market share estimates.
} 
ring to some findings from from the adjacent experimental and cartel literatures, on the role of firm numbers and size asymmetries.

In fact, the Commission's model, as identified above, resonates quite closely with the emerging message from the experimental literature on tacit collusion. Huck et al. (2004), surveying that literature, suggest that there is some evidence that tacit collusion can occur in duopoly settings, but that it is rarely found with more than two players. This result is also supported in their own experiments, in which collusion is sometimes found with only two firms, but with three, Nash equilibrium behaviour is usual, and with four or more, even more competitive behaviour is sometimes found. On asymmetries too, recent results from the experimental literature confirm an important dampening effect on the likelihood of collusion. For example, Fonseca and Norman (2008) report that, holding numbers constant at 2 or 3 , asymmetry leads to reduced prices. In their work, even amongst duopolists tacit collusion requires symmetry.

On the other hand, there is a marked contrast with what is known about real world cartels. Here, typically, far more than just two firms are involved. A variety of survey studies suggest that the median number of firms in prosecuted cartels lies between 5 and 8 (Davies and Olczak, 2008). The empirical cartel literature has paid relatively little attention to the extent of size asymmetries observed within detected cartels. However, from our own work on a sample of 41 prosecuted EC cartels (Davies and Olczak, 2008) it is clear that many real world cartels display far greater size asymmetries amongst cartel members than is found in our present merger sample: only five of these cartels lie within the region of collective dominance shown in figure $5 ; 11$ others lie within the SD region and the remaining 25 fall in the NI region.

This contrast is thought-provoking for both practitioners and academics. The ability of a cartel to accommodate larger number of asymmetric firms will depend on its internal monitoring and punishment mechanisms, and an improved understanding of those mechanisms by policy makers may provide 
insights into the conditions (if any) under which tacit collusion may yet be feasible in larger number asymmetric cases.

More generally, contrasting the literatures on hard-core and soft (tacit) collusion is thought-provoking in a number of respects - as has been previously highlighted by Harrington (2005, 2006(b)). An obvious question is: "how far are tacit collusion and cartels seen as substitutes?" Do firms only look to form cartels when the legally safer option of tacit collusion is unattainable? Is cartel formation sometimes provoked by a breakdown in tacit collusion? These questions also raise doubts whether the same theoretical model is appropriate for all forms of collusion. As again noted by Harrington (2005, slide 7), 'there is a gap between antitrust practice - which distinguishes explicit and tacit collusion and economic theory - which (generally) does not.' ${ }^{30}$ Empirically, this points to an intriguing, but difficult, future research agenda focused on the question: "are there well-defined (i.e. observable and predictable) differences between the conditions which give rise to tacit collusion, hard core collusion (cartels), and single dominance?"

\section{References}

Ashenfelter, O., Hosken, D., and Weinberg, M. (2009). Generating evidence to guide merger enforcement. Competition Policy International, 5(1):6785 .

Baxter, S. and Dethmers, F. (2006). Collective dominance under EC merger control - after Airtours and the introduction of unilateral effects is there still a future for collective dominance? European Competition Law Review, $27(3): 148-60$.

Bergman, M., Coate, M. B., Jakobsson, M., and Ulrick, S. W. (2009). At-

\footnotetext{
${ }^{30}$ See also, "Collusion: One Model Fits All", Davies and Hviid (May 2006), http://www . ccp.uea.ac.uk/publicfiles/Events/collusion_slides.pdf
} 
lantic divide of Gulf Stream convergence: merger policies in the European Union and the United States. Working paper. http://papers.ssrn.com/ sol3/papers. cfm?abstract_id=975102.

Bergman, M., Jackobsson, M., and Razo, C. (2005). An econometric analysis of the European Commission's merger decisions. International Journal of Industrial Organization, 23:717-37.

Bougette, P. and Turolla, S. (2008). Market structures, political surroundings, and merger remedies: an empirical investigation of the EC's decisions. European Journal of Law and Economics, 25(2):125-50.

Bresnahan, T. F. (1989). Empirical studies of industries with market power. Ch 17. in Handbook of Industrial Organization Vol. 2, Schmalensee, R., and Willig, R. (eds.),Elsevier.

Carlton, D. W. (2009). Why we need to measure the effect of merger policy and how to do it. Competition Policy International, 5(1):87-100.

Carree, M. A., Günster, A., and Schinkel, M. P. (2008). European antitrust policy: an analysis of Commission decisions during 1964-2002. Amsterdam Center for Law and Economics Working Paper(06).

Chamberlin, E. H. (1929). Duopoly: value where sellers are few. Quarterly Journal of Economics, 43:63-100.

Coate, M. B. (2005). Empirical analysis of merger enforcement under the 1992 merger guidelines. Review of Industrial Organization, 27:279-301.

Coate, M. B. and McChesney, F. S. (1992). Empirical evidence on FTC enforcement of the merger guidelines. Economic Enquiry, 30(2):277-93.

Coate, M. B. and Ulrick, S. W. (2006). Transparency at the Federal Trade Commission: the horizontal merger review process 1996-2003. Antitrust Law Journal, 73(2):531-70. 
Coate, M. B. and Ulrick, S. W. (2009). Influential evidence in merger enforcement at the Federal Trade Commission. In Issues in Competition Law and Policy. ABA Section of Antitrust Law.

Compte, O., Jenny, F., and Rey, P. (2002). Capacity constraints, mergers and collusion. European Economic Review, 46(1):1-29.

Davies, S. W., Driffield, N. L., and Clarke, R. (1999). Monopoly in the UK: what determines whether the MMC finds against the investigated firm? Journal of Industrial Economics, 47(3):263-83.

Davies, S. W. and Lyons, B. (2007). Mergers and merger remedies in the EU: assessing the consequences for competition. Edward Elgar.

Davies, S. W. and Olczak, M. (2008). Tacit versus overt collusion. Firm asymmetries and numbers: what's the evidence? Competition Policy International, 4(2):175-200.

Duso, T., Neven, D. J., and Röller, L.-H. (2007). The political economy of European merger control: evidence using stock market data. Journal of Law and Economics, 50:455-89.

Farrell, J. and Shapiro, C. (1990). Horizontal mergers: an equilibrium analysis. American Economic Review, 87:107-26.

Fonseca, M. and Normann, H.-T. (2008). Mergers asymmetries and collusion: experimental evidence. Economic Journal, 118(1):287-400.

Greene, W. H. (2008). Econometric analysis. Pearson Prentice Hall.

Grout, P. and Sonderegger, S. (2005). Predicting cartels. A report prepared for the Office of Fair Trading. OFT 773.

Harrington, J. E. J. (2005). The collusion chasm: reducing the gap between antitrust practice and industrial organization theory. Presentation at the 
Csef-Igier Symposium on Economics and Institutions.http://www.econ . jhu.edu/People/Harrington/Capri.ppt.

Harrington, J. E. J. (2006a). How do cartels operate? Foundations and Trends in Microeconomics, 2(1):1-105. http://www.econ.jhu.edu/ People/Harrington/fnt06.pdf.

Harrington, J. E. J. (2006b). The anatomy of a cartel price path: theory meets practice. Keynote speech to EARIE conference, Amsterdam.http: //www. econ.jhu.edu/People/Harrington/earie2006keynote.pdf.

Huck, S., Normann, H.-T., and Oechssler, J. (2004). Two are few and four are many: numbers effects in experimental oligopolies. Journal of Economic Behavior and Organization, 53:435-46.

Ivaldi, M., Jullien, B., Rey, P., Seabright, P., and Tirole, J. (2003). The Economics of Tacit Collusion. Report for DG Comp, European Commission.

Khemani, R. S. and Shapiro, D. M. (1993). An empirical analysis of Canadian merger policy. The Journal of Industrial Economics, 41(2):161-77.

Kühn, K.-U. (2001). An economist's guide through the joint dominance jungle. University of Michigan Legal Working Paper Series, 2(14).

Kühn, K.-U. (2004). The co-ordinated effects of mergers in differentiated products market. University of Michigan Legal Working Paper Series, 34.

Levenstein, M. C. and Suslow, V. Y. (2006). What determines cartel success. Journal of Economic Literature, 44(1):43-95.

Lindsay, A., Leechi, E., and Williams, G. (2003). Econometric study into European Commission merger decisions since 2000. European Competition Law Review, 24(12):673-82.

Rothschild, R. (1999). Cartel stability when costs are heterogeneous. International Journal of Industrial Organization, 17:717-34. 
Salant, S., Switzer, S., and Reynolds, R. (1983). Losses from horizontal merger: the effect of an exogenous change in industry structure on Cournot-equilibrium. Quarterly Journal of Economics, 98:185-99.

Scherer, F. M. and Ross, D. M. (1970). Industrial Market Structure and Economic Performance. Rand McNally \& Co.

Slade, M. E. (1987). Interfirm rivalry in a repeated game: an empirical test of tacit collusion. The Journal of Industrial Economics, 35(4):499-516.

Slade, M. E. (2004). Market power and joint dominance in UK brewing. The Journal of Industrial Economics, 52(1):133-63.

Vasconcelos, H. (2005). Tacit collusion, cost asymmetries, and mergers. RAND Journal of Economics, 36(1):39-62.

Weir, C. (1992). Monopolies and Mergers Commission, merger reports and the public interest: a probit analysis. Applied Economics, 24:27-34.

Weir, C. (1993). Merger policy and competition: an analysis of the Monopolies and Mergers Commission's decisions. Applied Economics, 25:57-66. 
Figure 1: Commission decisions

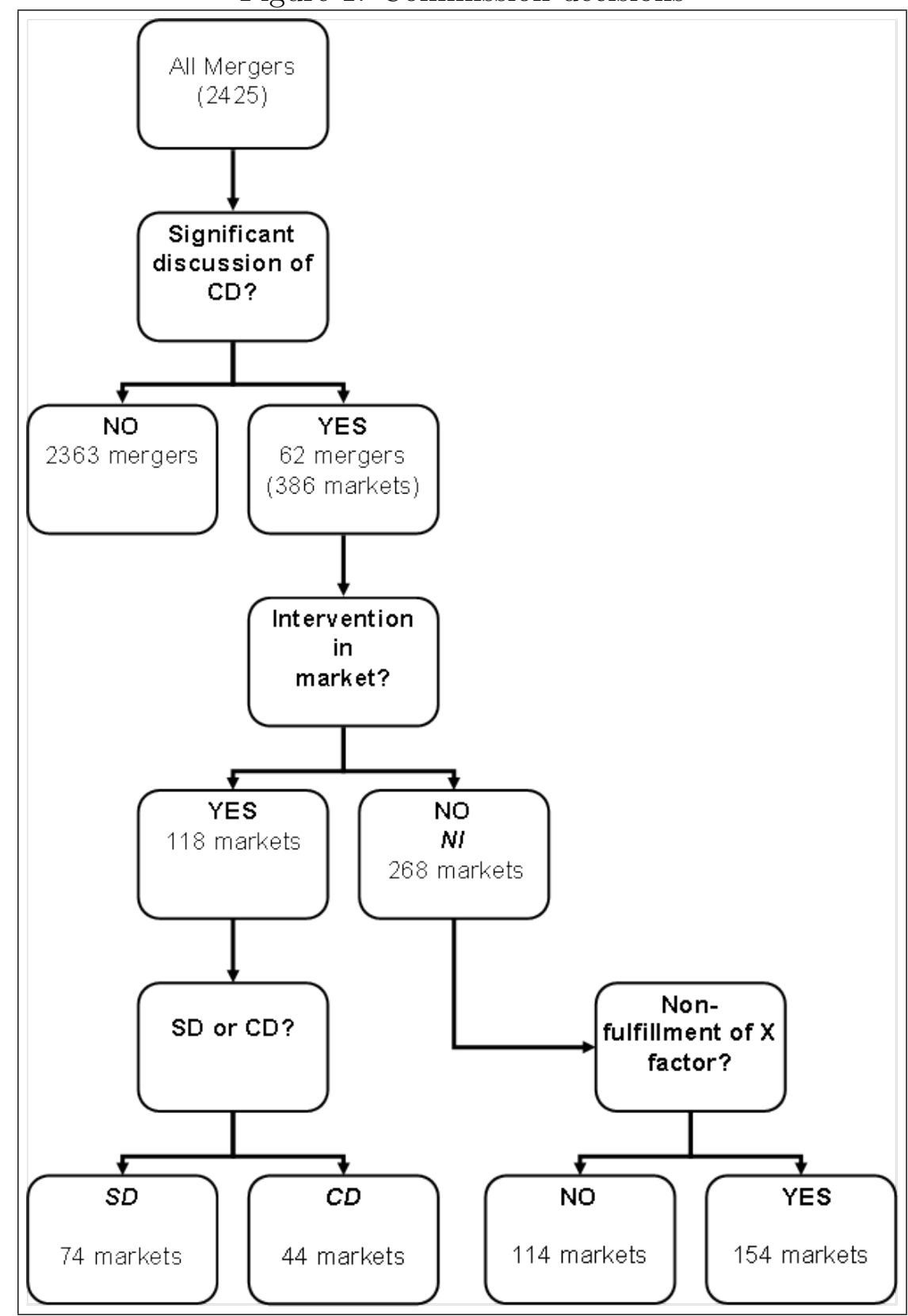


Table 1: Non-intervention markets in which the checklist is not satisfied

\begin{tabular}{lc}
\hline & Number of markets \\
\hline Total non-intervention markets & 268 \\
Of which checklist not satisfied & 154 \\
\hline Reasons & \\
\hline Easy entry & 74 \\
Countervailing buyer power & 73 \\
Lack of price transparency & 60 \\
(incl. bidding \& tendering markets) & \\
Rival excess capacity & 35
\end{tabular}

NB the total of the individual citations exceeds the number of markets because some markets involve more than one factor.

Figure 2: The oligopoly triangle

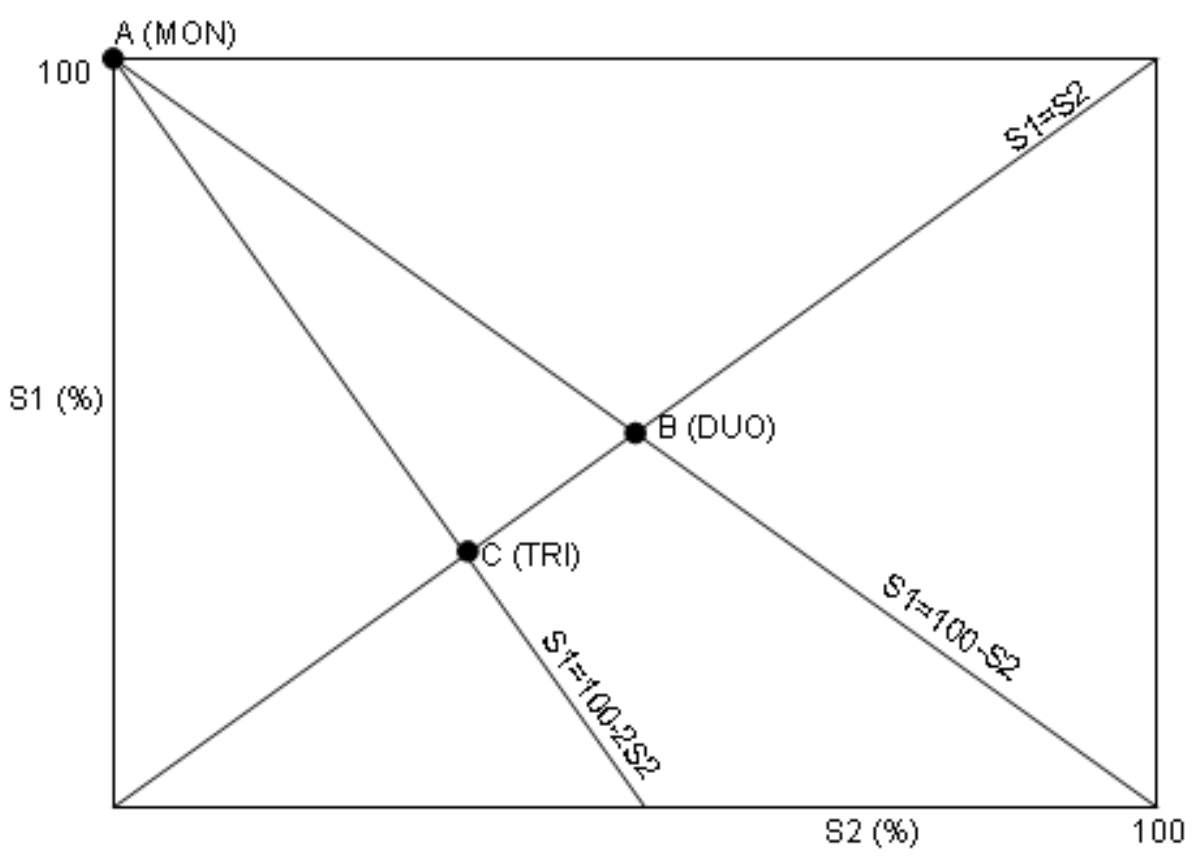


Figure 3: Iso- $H H I$ curves in the oligopoly triangle

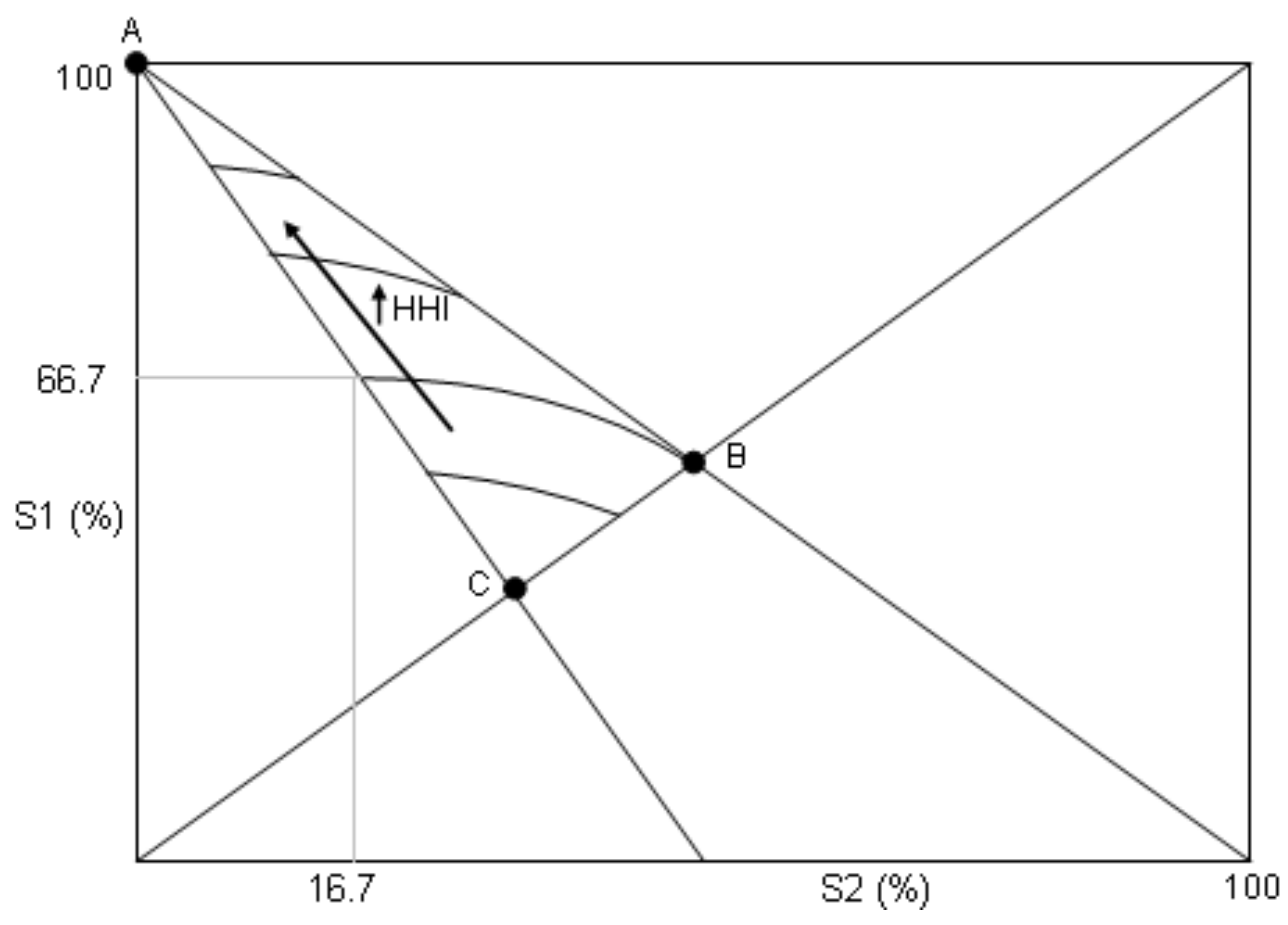


Figure 4: The sample markets and decisions

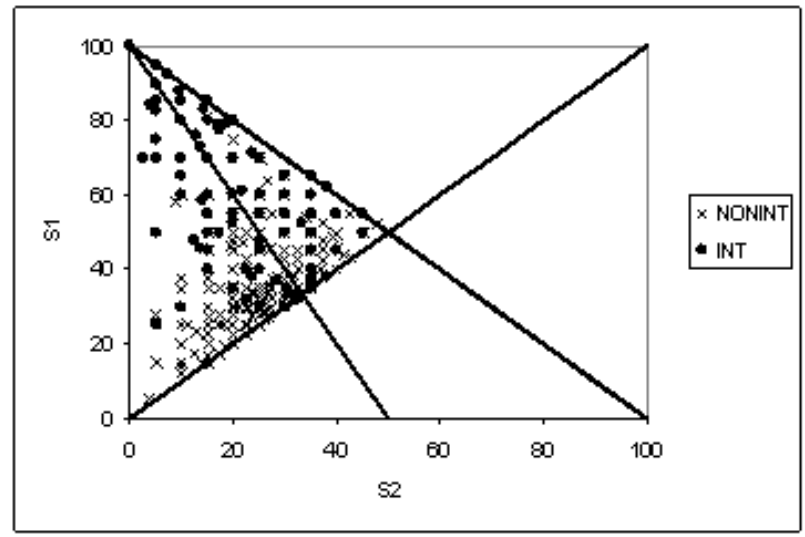

(a) All markets

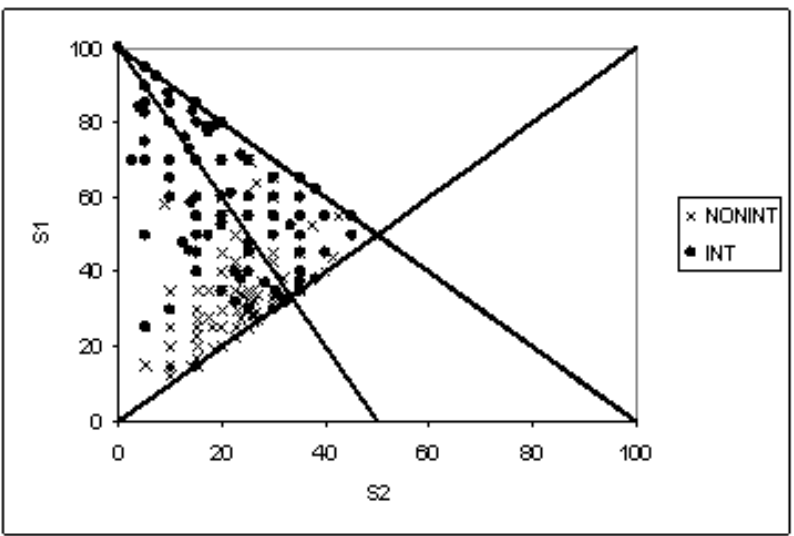

(b) Markets for which the checklist is satisfied

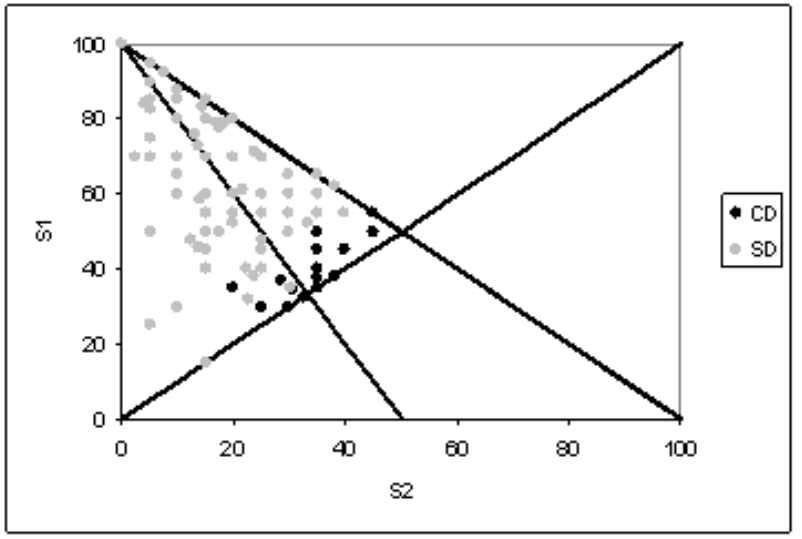

(c) Intervention markets 
Table 2: Multinomial logit results

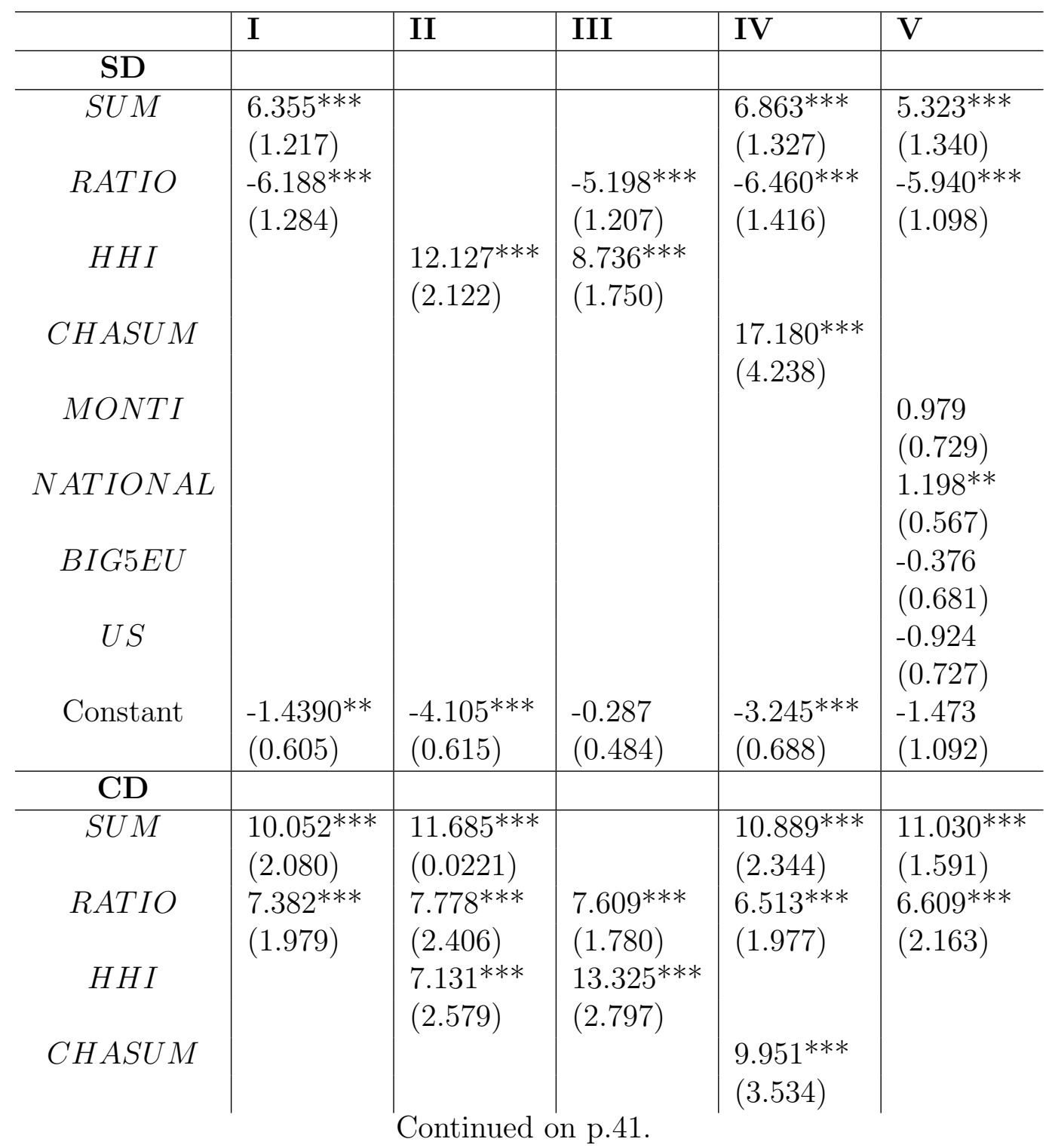


Continued from p.40.

\begin{tabular}{c|l|l|l|l|l}
\hline & I & II & III & IV & V \\
\hline MONTI & & & & & 0.155 \\
NATIONAL & & & & \\
& & & & $0.989)$ \\
BIG5EU & & & & $(1.122)$ \\
& & & & 1.883 \\
US & & & & $(1.312)$ \\
& & & & -0.974 \\
Constant & $-13.899^{* * *}$ & $-3.264^{* * *}$ & $-10.973^{* * *}$ & $-14.628^{* * *}$ & $(1.048)$ \\
& $(1.963)$ & $(0.761)$ & $(1.857)$ & $(1.791)$ & $\left(3.0393^{* * *}\right.$ \\
\hline$N$ & 232 & 232 & 232 & 179 & 232 \\
\hline Pseudo $R^{2}$ & 0.454 & 0.250 & 0.437 & 0.487 & 0.509 \\
Log-L & -123.627 & -170.030 & -127.537 & -90.340 & -111.306 \\
Wald $\chi^{2}$ & $110.99^{* * *}$ & $54.92^{* * *}$ & $121.30^{* * *}$ & $146.98^{* * *}$ & $146.98^{* * *}$ \\
\hline Correct predictions (\%) & & & & & \\
\hline All & 81 & 69 & 76 & 77 & 82 \\
SD & 77 & 65 & 76 & 75 & 81 \\
CD All & 80 & 32 & 57 & 66 & 80 \\
CD-DUO \& TRI & 69 & 0 & 34 & 58 & 69 \\
CD-LINKS ${ }^{\circ}$ & 100 & 93 & 100 & 100 & 100 \\
NI & 84 & 86 & 84 & 82 & 83 \\
\hline & & & & &
\end{tabular}

***Significantly different from 0 at $1 \%$ level, ** significantly different from 0 at $5 \%$ level and ${ }^{*}$ significantly different from 0 at $10 \%$ level. Standard errors in parenthesis. Equations are estimated with observations clustered by merger.

$\checkmark$ Recall from section 3 above, that CD-LINKS cases are treated as SD in the sense that the Commission asks, in effect, whether the linked firms are singly dominant if their shares are combined. This is how they are classified in these equations. In experiments, not shown here, all equations were re-estimated excluding the 15 such cases concerned - all coefficient estimates and significance were virtually identical to those shown here. 
Figure 5: Predicted decisions within the triangle (from eqn. I, Table 2)

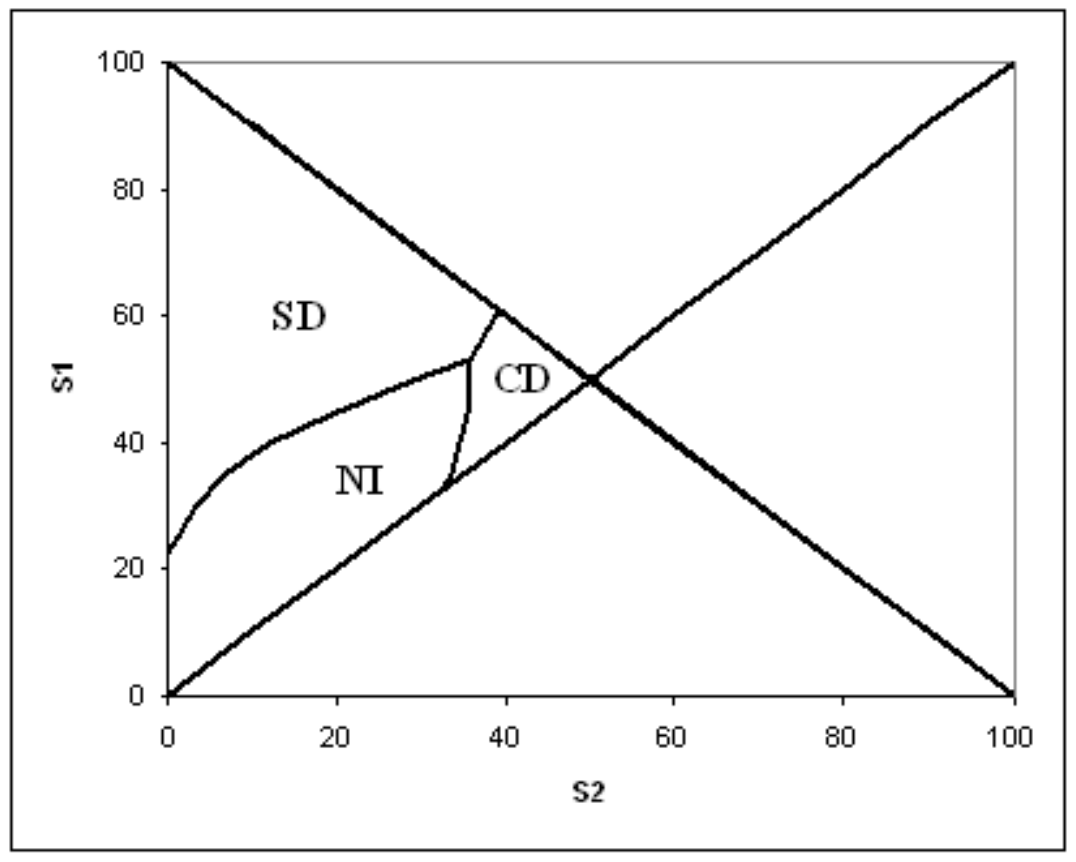

